\title{
Pater, pátria e a memória como patrimônio: sobre K.: relato de uma busca, de Bernardo Kucinski
}

Vincenzo Russo ${ }^{1}$

\author{
Anger, \\ as black as a hook, \\ overtakes me. \\ Each day, \\ each Nazi \\ took, at 8: 00 A.M., a baby \\ and sauteed him for breakfast \\ in his frying pan.
}

And death looks on with a casual eye and picks at the dirt under his fingernail.
Man is evil,
I say aloud.
Man is a flower
that should be burnt,
I say aloud.
Man
is a bird full of mud,
I say aloud.

And death looks on with a casual eye and scratches his anus.
Man with his small pink toes, with his miraculous fingers
is not a temple
but an outhouse,
I say aloud.
Let man never again raise his teacup.
Let man never again write a book.
Let man never again put on his shoe.
Let man never again raise his eyes,
on a soft July night.
Never. Never. Never. Never. Never.
I say those things aloud.

I beg the Lord not to hear.

Anne Sexton, After Auschwitz

${ }^{1}$ Doutor em literatura portuguesa e brasileira e professor associado da Università degli Studi di Milano, Milão, Itália. E-mail: vincenzo.russo1@unimi.it 


\section{K. como Kucinski?}

O romance (romance?) de Bernardo Kucinski K.: relato de uma busca (2011), considerado já uma espécie de clássico da contemporaneidade brasileira, tanto pela recepção interna (várias edições, debate crítico e acadêmico etc.) como pela projeção no exterior (várias traduções nas principais línguas: espanhol, inglês, alemão e, recentemente, também para italiano), é um desafio crítico pelas inúmeras questões que levanta e pelas plúrimas abordagens que potencialmente abre.

Começarei explicando um pouco o trocadilho que está no título e que me dará a possibilidade de, por um lado, destacar o objeto de análise e, por outro, abrir o campo para a conceptualização mínima que me interessa utilizar como chave de interpretação do romance em questão.

A evidente homologia da raiz etimológica dos três termos pater, "pátria" e "patrimônio" é muito tentadora para abordar um texto-paradigma para a compreensão das modalidades de construção dos processos memoriais a que chamamos de pós-memória num contexto histórico e cultural como o Brasil contemporâneo. Por pós-memória - alargando um pouco o conceito que Marianne Hirsch (2006) aplicou às tecnologias das recordações dos sobreviventes da shoah e de seus descendentes - entenda-se a relação dos filhos de quem sobreviveu a um evento traumático (quer cultural, quer coletivo) com as experiências vividas pelos pais. Experiências de quem guarda memórias graças às histórias e às imagens com as quais cresceram e que tiveram uma força tão poderosa que se transformaram em verdadeira recordação. No Brasil contemporâneo, a pós-memória pode, por exemplo, explicar os complexos processos de construção das memórias dos que vieram depois do estado de exceção político e civil representado pela Ditadura Militar (1964-1985). Uma literatura da pós-memória, apesar de ser um campo ainda fluído, vai emergindo hoje em dia no Brasil no âmbito do debate mais amplo sobre as heranças da Ditadura Militar na sociedade contemporânea. Se é já amplamente estudada a literatura testemunhal produzida durante a Ditadura Militar ou mesmo depois pelas geraçõestestemunho, formando o arquivo da memória cultural da Nação, resta ainda por mapear a constelação de representações literárias produzida pela geração que não viveu a Ditadura, mas formou sua consciência e seu imaginário sobre esse passado por meio das memórias dos pais. Essas memórias transmitidas de uma geração para a outra (mesmo que parcialmente) constituem-se em narração pós-memorial. 
Sem dúvida, o caso de K.: relato de uma busca, de Bernando Kucinski, representa um texto-chave para a compreensão dos mecanismos memoriais introjetados, expulsados ou apenas silenciados pela consciência nacional brasileira sobre as violências do regime militar. Esse também é um romance que desloca a questão da memória para um plano mais complexo e sofisticado: quem é o sujeito da memória? Quem lembra os acontecimentos passados nesse annus horribilis (1974) para os opositores do regime, como testemunham os fatos de Araguaia? Quem lembra é o mesmo sujeito que fala, isto é, que conta?

A inscrição da história pelo "literário" permite ao autor-Kucinski - que, enquanto cidadão-Kucinski, foi testemunha da repressão política durante a ditadura - atribuir na ficção literária à figura de um pai (o próprio K.) a memória de uma filha (em que se entrevê a figura histórica da irmã): o testemunho histórico se transforma em narração, isto é, vocaliza sua fala $a$ posteriori quase com quarenta anos de atraso. O silêncio das testemunhas muitas vezes não é (ou não foi) menos ruidoso que sua tomada de palavra, como nos ensinam alguns textos da literatura testemunhal considerados canônicos pelos shoah's studies. O silêncio da testemunha pode produzir ou apenas deslocar o esquecimento, pode converter-se em pós-memória.

A ficção literária permite deslocar o sujeito da memória para a figura paterna, que, por um absurdo crono-lógico, ${ }^{2}$ sobrevive à filha e carrega o dever da lembrança, de uma pós-lembrança, já não, como seria normal, da geração posterior, mas da geração anterior. O deslocamento do sujeito da memória talvez tenha a ver com a survivor syndrom (Weinrich, 2010, p. 262) que K., enquanto pai, consegue contornar com auxílio das estratégias narrativas e afetivas. Por meio delas, ao elaborar o luto da ausência que a máquina estadual continua a presentificar (cartas do Banco que o correio regularmente entrega à filha defunta), K. não aspira uma tansferência integral da memória da filha, mas garante "a permanência do seu nome no rol dos vivos" como "produto do esquecimento coletivo do rol dos mortos" (Kucinski, 2011, p. 17).

\section{Ler a letra $\mathrm{K}$.}

Desde sua publicação em 2011, o romance recebeu muita atenção crítica não bastasse sua "contribuição relevante para a rearticulação da

2 “Os filhos é que deviam enterrar os pais e não os pais enterrarem os filhos” (Kucinski, 2011, p. 88). 
memória brasileira em tempos de 'Comissão de Verdade', com seus avanços e contradições" (Aguiar, 2011). A crítica, mesmo a crítica jornalística, focou na complicada relação entre relato "literário" e o vivido biográfico, destacando o quiasmo de laços familiares entre o protagonista do livro, K., e a filha (nunca nomeada no livro a não ser com a letra R. no fim de uma carta), deixando entrever - como aliás procura fazer o próprio livro - atrás da narração literária a história verdadeira e familiar de Bernardo Kucinski, que viveu a perda e a desaparição da irmã Ana Rosa e do cunhado Wilson Silva pela repressão política em 1974 (Oliveira, 2013).

O incipit do livro, tão paradigmático por um lado e tão constrangedor por outro, tendo em vista sua cristalina simplicidade "Tudo neste livro é invenção, mas tudo aconteceu" -, parece ser a chave de leitura que informa toda a interpretação de K.: relato de uma busca, como texto literário que suplementa os vazios, o vácuo da história, o défice de narração histórica através do (dir-se-ia) fácil recurso à função da testemunha, cuja memória, ainda que falível, parcial e precária, contribuiria - mais que para reconstruir o inventário de memórias pessoais - para mapear "o inventário de perdas, da perda de uma vida" (Kucinski, 2011, p. 15-16). De forma semelhante à comovida dedicatória "às amigas que a perderam", o arquivo da memória, pelo menos como tradicionalmente se conota na história cultural, formula seu estatuto por negação: arquivar, organizar memórias não é construir, não é um trabalho de adição, de acumulação, mas, sim, de subtração, de perdas: "um universo de afetos se desfez". O esquecimento também tem seus direitos, às vezes invisíveis, às vezes indizíveis.

Parece que a dissolução entre o real (que o próprio título protocolar de "relato" parece estratificar) e o fictício ("tratar os fatos como literatura e não como história") seja a melhor estratégia não só para não cair na armadilha do memorialismo (Vecchi, 2014) mas também para reabilitar a fabulação, aliás, a reivindicação da literatura como direito de contar para não esquecer: reivindicação que está presente nas três epígrafes extraídas das obras de, respectivamente, Guimarães Rosa, Pessoa e Mia Couto, com dimensão tão legítima quanto a historiografia ao narrar a história.

Quando Kucinscki chama a atenção do "caro leitor" sobre o fato de que "há referências a documentos em apenas duas histórias e somente como recurso narrativo" (Kucinski, 2001, p. 13), podemos evocar a 
posição de Hayden White, segundo o qual, a persistência da narratividade na representação da realidade é um valor em si (White, 2006, p. 24). Os documentos históricos (pesquisas, registros da época) não garantem uma opacidade menor em relação ao fluxo narrativo na interpretação da realidade.

A crítica também privilegiou, por um lado, a natureza da estrutura fragmentária (antologia de contos de que fala Flávio Aguiar), cuja unidade é dada apenas pela figura do protagonista K., e por outro, demorou-se - como é óbvio - sobre a tensão entre testemunho, denúncia e literatura (para usar as palavras do Renato Lessa, no posfácio da obra na edição da Cosac Naify), ilustrando os processos memorativos ligados à desaparição de uma filha, os trabalhos de luto que giram em torno da data da perda (abril de 1974), a constelação recalcada das feridas do homem e do pai, os passados subtraídos (Vecchi, 2014), a impossibilidade do perdão em nome da amnésia juridicamente formulada na Lei da Anistia (de 1979) acerca da reconciliação da comunidade brasileira (Manacorda, 2015) - essa amnésia a que Kucinski chama, com uma poderosa imagem patológica, de "Alzheimer nacional".

\section{O pai e as memórias das pátrias}

Pater é equivalente a "pai" em latim, e sua raiz etimológica provém do sânscrito PA que implica o conceito de proteger e, ao mesmo tempo, nutrir: pai, portanto, é quem protege, sustenta a família. O pater dos latinos é usado também para os velhos, os senadores, os heróis e os deuses - Jup-piter é Iovis-Pater. Atribuir ao pai nomeado apenas a letra $\mathrm{K} .^{3}$ tem, obviamente, muitas ressonâncias simbólicas, disseminadas pelo texto ao longo de múltiplas referências, que têm a ver com o alfabeto dos afetos familiares. Aliás, a busca da filha vai-se desenhando como uma romaria de ausências, uma sucessão de etapas que não obedece à cronologia, um tempo-espaço esvaziado que a tecnologia das recordações desencadeada pela memória paternal só muito a custo consegue preencher. Ao longo da narração, o protagonista K. encena a culpa de já não ser ou nunca ter sido "pater", isto é, o pai protetor que sustenta e nutre a família.

\footnotetext{
${ }^{3}$ Tal como se intitula um belíssimo poema de Drummond "K.": "Uma letra procura/o calor do alfabeto. Uma letra perdida /no palor da estalagem //...Uma letra inapelada que exprime tudo, e é nada".
} 
A filha confiara na outra família, não nele. Para a outra família o casamento não fora secreto, mas apenas discreto. Havia nisso um significado maior, teria ela sinalizado uma troca de famílias? Esse pensamento o machucava. Teria sido uma resposta ao seu segundo casamento com aquela alemã que a filha detestava? Ou a sua devoção tão intensa à língua iídiche? Uma língua que nem ela nem os seus irmãos sabiam falar - aliás por culpa dele que não se preocupou em lhes ensinar. Essa hipótese somava mais culpas à sua culpa (Kucinski, 2011, p. 48).

Todavia é à figura do pai que Kucinski demanda a memória da filha desaparecida, é o pai quem guarda e possui a memória familiar da filiação: "Para o pai, com qualquer armação de óculos a filha era a mais linda das meninas do colégio. Um anjo de formosura, ele também dizia" (Kucinski, 2011, p. 43).

A função protetora do pai, explicitada pela incansável busca da filha desaparecida (ou pelo menos na procura de notícias dela quer como pessoa viva quer apenas como corpo morto), liga-se, não só através das implicações semânticas mas também pela configuração antropomórfica, ao termo/conceito de pátria - a terra dos "pais" -,termo que "arrasta consigo uma forte carga afetiva, resultante da sobredeterminação sacrofamiliar que o recobre, ancestralidade que tinha o seu ponto nodal no culto dos túmulos" (Catroga, 2008, p. 9).

Se é verdade que, ao privilegiar a origem e a herança, a pátria é, sobretudo, memória - entendida como instância que enlaça, retrospectivamente, os vivos e os mortos numa cadeia de solidariedade através da qual os indivíduos se reconhecem como com-patriotas de uma mesma terra, a terra dos pais -, em K.: relato de uma busca, assistimos à dupla perda ou negação das pátrias (Polônia e Brasil). A citabilidade da pátria é assegurada por uma língua fantasmática, "essa língua-cadáver", como o í́diche, que o protagonista K. leva consigo para o Brasil, enquanto imigrado judeu foragido da Polônia devido à perseguição política no contexto dos preparativos da Segunda Guerra Mundial. Ele salva a língua para si e por si, cultuando sua literatura, mas não sua acessibilidade e transmissibilidade familiar, pois, como escreveu Rachel Ertel: "o iídiche já não é língua materna de ninguém ou de quase ninguém. Hoje já não se transmite, portanto, o iídiche, mas sua própria ausência. E é essa ausência que é hereditária" (Ertel, 2001, p. 82). 
As duas pátrias negadas ao pai e à filha estão ligadas pelo duplo fio da memória paterna, que interpreta a violência do presente através da violência do passado. $\mathrm{O}$ ato de comparar o incomparável (tal como pretende uma certa vulgata crítica dos estudos sobre a shoah) é levado até ao extremo por Kucinski, que não só compara o sistema nazista com o sistema ditatorial brasileiro mas reconhece, ainda, que esse último fica aquém do comparável: "Sente com nó no peito que algo escabroso aconteceu, ao ponto de assustar e fazer recuar as pessoas que queriam ajudar - sente que sua filha foi tragada por um sistema impenetrável, diferente de tudo o que ele havia conhecido, mesmo na Polônia" (Kucinski, 2011, p. 43). ${ }^{4}$

Se é certo dizer que hoje em dia a shoah está deixando de ser interpretada como "exceção" para ser cada vez mais assumida como "paradigma", em termos analíticos, em relação a outra violências, é também indiscutível que, em termos de memória cultural, ela continua a atuar em contextos "outros e periféricos" com a mesma força de "massacre ontológico" (para usar a expressão de George Steiner) que ilumina as violências das desaparições nos regimes militares sulamericanos: comparar significa estudar as formas de violência, insistir na incomparabilidade é apenas cultuar a shoah como objeto de comemoração, lamentação e interpretação limitada (Traverso, 2006, p. 176).

Esse rabino quer dizer que minha filha não era pura? O que ele sabe da minha filha... nada. Para K., o rabino fala palavras vazias. Já lhe haviam dito na Sociedade do Cemitério, a Chevra Kadisha, que sem corpo não se podia colocar a matzeivá. Ele retrucara ao Avrum, o secretário da sociedade, que na entrada do cemitério do Butantã há uma grande lápide em memória dos mortos do Holocausto, e debaixo dela não há nenhum corpo. Avrum o amoestara por comparar o que aconteceu com a sua filha ao Holocausto, nada se compara ao Holocausto, disse; chegou a se levantar, tão aborrecido ficou. O Holocausto é um e único, o mal absoluto. Com isso $\mathrm{K}$. concordou, mas retrucou que para ele a tragédia da sua filha era a continuação do holocausto (Kucinski, 2011, p. 43).

\footnotetext{
${ }^{4}$ Já no capítulo primeiro, "Sorvedouro de Pessoas", ao tomar consciência de que a desaparição da filha foi um abuso do regime, o imaginário experiencial e histórico de $\mathrm{K}$. chega a ler em contraponto as execuções em massa dos nazistas e o sumidouro de pessoas do regime militar, esclarecendo que "até os nazistas, que reduziam suas vítimas a cinzas, registavam os mortos". Parece que K. prefira a contabilidade macabra do massacre à "agonia da incerteza" (Kucinski, 2011, p. 27).
} 
A pátria negada do pai e ao pai é o contraponto da pátria negada da filha e à filha: o Brasil da salvação/redenção do pai se transformou no "servedouro das pessoas" para a filha e para todos os opositores do regime. A inversão trágica que revela como na pátria-Brasil é impossível sepultar e cultuar os próprios defuntos (e, portanto, espaço negando-se a si mesmo como pátria) ilumina o processo do triplo abandono a que K. se vê submetido:

1) Negação da sepultura do cadáver: “Os filhos é que deviam enterrar os pais e não os pais enterrarem os filhos. Pior que nem isso, nem enterrar podemos" (Kucinski, 2011, p. 88).

2) Negação das inscrições da memória cultual da filha: a Matzeivá é a lápide colocada no túmulo um ano depois do sepultamento e a comunidade judaica não permite ao K. a fixação na terra, no chão da lápide sem haver corpo, sem cadáver. Espectros, mesmo familiares, não podem ser sepultados, porque, segundo as palavras do rabino, "o que é sepultamento, senão devolver à terra o que veio da terra? Adam, adamá, homem e terra [...] Não tem sentido sepultamento sem corpo" (Kucinski, 2011, p. 80).

3) Negação da escrita não por ser em iídiche, mas por querer edificar um livro impossível: um livro sobre a tragédia da sua filha. O bloqueio não é linguístico, mas moral. Inversão das leis do esquecimento: não escrever é lembrar de outra forma.

Queria relatar às netas em Eretz Israel tudo o que havia acontecido. E as netas não conheciam o iídiche, só o hebraico. Naquela mesma noite, $\mathrm{K}$. escreveu sua primeira carta à neta em Eretz Israel, em hebraico impecável, como ele aprendera de criança no heder. Assim, não era mais o escritor renomado a fazer literatura com a desgraça da filha; era o avô legando para os netos o registro de uma tragédia familiar (Kucinski, 2011, p. 134).

\section{Patrimônio como memória}

Chegamos enfim ao último conceito que nos ajudará a abrir mais pistas na interpretação de um texto tão fértil e tão complexo como K.: a memória como patrimônio. De fato, se a reconstrução do traumático acontecimento individual da desaparição forçada da filha dentro da 
opacidade dos factos históricos é atribuída à memória do velho pai, essa memória se reconfigura inclusive etimologicamente como dever, ofício, tarefa do pai, isto é patrimônio. Não interessa aqui desbravar por completo um conceito tão estratificado semanticamente e com conotações disciplinares tão diferentes (Ribeiro e Rossa, 2015). O que a conceptualização do termo patrimônio (a partir da sua etimologia) nos permite fazer é iluminar alguns lugares textuais (até marginais no contexto da narração) do romance que, a nosso ver, funcionam como um suplemento de significações interpretativas. A memória patrimonial, que confere a toda a textualidade uma configuração original e tem como contraponto o legado material (conscientemente ou inconscientemente deixado pela filha como herança ao pai, como os cartões e as cartas do banco ou a família do marido), reconstrói por rastos, por fragmentos, as vicissitudes históricas da busca. Se considerarmos esse dever do pai como patrimônio, esse dever de recordar e de contar, não podemos também deixar de ligar a construção etimológica da palavra patrimônio - composta por pater e munus, "dever", obrigação para com alguém, dom não no sentido de donus, enquanto "presente", mas como dever, obrigação (Esposito, 2006) -, com dois momentos do romance que se tornam particularmente paradigmáticos na articulação da narração. Esse conceito de munus se liga com a palavra portuguesa mancomunados (que implica uma ideia de conluio e cumplicidade entre duas ou mais pessoas em ações pouco desejáveis) a que o protagonista $K$. se refere para definir a rede de informantes que jogam com a boa-fé do velho pai, disposto a acreditar em qualquer indício que o conduza à verdade: até que a filha se encontra em Portugal por ocasião da Revolução dos Cravos (abril de 1974). “Montaram uma farsa. Um teatro para me torturar. Estão todos mancomunados, esses informantes. É uma rede sórdida, que vão todos para o inferno 'zeln zein ale guein in dred arain' pragueja em iídiche" (Kucinski, 2011, p. 134).

Mas munus tem também a ver com imunidade, outro termo-chave para compreender a atitude que depois de meses de busca vã, $\mathrm{K}$. vai assumindo.

O sorvedouro de pessoas não para, a repressão segue cruenta, mas o pai que procura sua filha teme cada vez menos. Desgraçado, mas insolente, percebe então o grande paradoxo da sua imunidade. Qualquer um pode ser engolido pelo sorvedouro de pessoas, ou atropelado ou despejado num buraco qualquer menos ele. Com ele 
a repressão não mexe, mesmo quando grita. Mexer com ele seria confessar, passar recibo (Kucinski, 2011, p. 90).

Imunidade, segundo o filosofo Roberto Esposito, implica isenção ou derrogação, isto é, a condição de imune é a de quem está a salvo das obrigações, dos perigos e dos riscos que envolvem todos os outros.

Por muito que lutou, pela sua exposição nacional e internacional contra os crimes da ditadura, $\mathrm{K}$. já pode contar com a imunidade para com os riscos da repressão. Na verdade é o próprio sistema ditatorial que está imune do contágio que a campanha midiática de K., na infinita busca pela filha, pode provocar. Não intervir para calar K. é a melhor defesa que o sistema tem para não correr riscos: "Mexer com ele seria confessar, passar recibo". A imunidade de que goza o cidadão K. está contraimunizada pelo sistema repressivo, que, como diz Kucinski na última linha do romance, ainda está articulado.

\section{Referências}

AGUIAR, Flávio (2011). O livro do Bernardo. Carta Maior, São Paulo, 28 out. On-line. CATROGA, Fernando (2008). Pátria, Nação e Nacionalismo. In: TORGAL, Luís Reis; PIMENTA, Fernando Tavares; SOUSA, Julião Soares (Coord.). Comunidades imaginadas. Nação e nacionalismo em África. Coimbra: Imprensa da Universidade de Coimbra, p. 9-39.

ERTEL, Rachel (2001). Le yddish. La langue de la crypte. Les Temps Modernes, n. 615, p. 75-89.

ESPOSITO, Roberto (2006). Communitas. Origine e destino della Comunità. Torino: Einaudi.

HIRSCH, Marianne (2006). Immagini che sopravvivono: le fotografie dell'Olocausto e la post-memoria. In: CATTARUZZA, Marina et al. (Org.). Storia della Shoah. La crisi dell'Europa, lo sterminio degli ebrei e la memoria del XX secolo. Torino: UTET, v. 4, p. 385-431.

KUCINSKI, Bernardo (2011). K.: relato de uma busca. São Paulo: Estrela Polar.

MANACORDA, Júlia (2015). A negatividade a dar conta do real. Revista Contemporânea, Niterói, ano 5, v. 1, n. 7, p. 1-16. 
OLIVEIRA, Tiago de (2013). Narrar o luto, resistir ao esquecimento. Revista Espaço Acadêmico, Maringá, v. 13, n. 151, p. 94-95.

RIBEIRO, Margarida Calafate; ROSSA, Walter (Org.) (2015). Patrimónios de influência portuguesa: modos de olhar. Coimbra: Imprensa da Universidade de Coimbra; Lisboa: Fundação Calouste Gulbenkian; Niterói: Editora da Universidade Federal Fluminense.

TRAVERSO, Enzo (2006). Comparare la Shoah: questioni aperte. In: CATTARUZZA, Marina et al. (Org.). Storia della Shoah. La crisi dell'Europa, lo sterminio degli ebrei e la memoria del XX secolo. Torino: UTET, v. 4, p. 167-199.

VECCHI, Roberto (2014). O passado subtraído da desaparição forçada: Araguaia como palimpsesto. Estudos de literatura brasileira contemporânea, Brasília, n. 43, p. 133-149.

WHITE, Hayden (2006). Forme di storia. Dalla realtà alla narrazione. Organização de E. Tortarolo. Roma: Carocci.

WEINRICH, Harald (2010). Lete: arte e critica dell'oblio. Tradução de F. Rigotti. Bologna: Il mulino. Ttítulo original: Lethe: Kunst und Kritik des Vergessens.

Recebido em janeiro de 2016.

Aprovado em junho de 2016.

\section{resumo/abstract/resumen}

\section{Pater, pátria e a memória como patrimônio: sobre K.: relato de uma busca, de Bernando Kucinski}

Vincenzo Russo

Existe uma memória de gênero? Existe uma memória masculina e/ou feminina? E o que acontece quando as memórias de um pai resgatam (ou tentam resgatar) a fragmentariedade das experiências da filha articuladas num tempo pessoal e subjetivo mas pontuadas pelos tempos traumáticos da História, ainda por mais da História da Pátria, da história-pátria? K.: relato de uma busca, de Bernando Kucinski, representa um dispositivo não só literário para tentar ensaiar algumas destas questões, como as da memória ou da pós-memória do supérstite, que são centrais no debate contemporâneo brasileiro.

Palavras-chave: memória, ditadura, gênero, Bernando Kucinski. 


\section{Pater, homeland and memory as heritage: about $K$.: relato de uma busca, de Bernando Kucinski}

\section{Vincenzo Russo}

Can a gendered memory exist? Can a masculine and/or femine memory exist? And what happens when the memories of a father salvage (or try to salvage) the fragmentary experiences of a daughter, articulated in a personal and subjective time but punctuated by traumatic moments in history, in particular, within national history? K.: relato de uma busca by Bernando Kucinski, is a not only a literary text but a political and cultural expedient that attempts to try to broach some of the above cited issues, such as the survivor's memory or post-memory, questions that are central in Brazil's contemporary discussions about the past.

Keywords: memory, Brazilian dictatorship, gender, Bernardo Kucinski.

\section{Pater, patria y la memoria como patrimonio: acerca de K.: relato de uma busca, de Bernando Kucinski}

\section{Vincenzo Russo}

¿Existe una memoria de género? ¿Existe una memoria masculina y/o femenina? ¿Y qué pasa cuando las memorias de un padre rescatan (o tratan de rescatar) las experiencias fragmentarias de la hija articuladas en un tiempo personal y subjetivo, pero interrumpidas por los momentos traumáticos de la Historia, la historia del país, de la patria? K.: relato de uma busca, de Bernardo Kucinski, es un dispositivo no sólo literario, sino político y cultural, que intenta proponer algunas de estas cuestiones, como la de la memoria o de la posmemoria de los sobrevivientes, que son centrales en el debate brasileño contemporáneo.

Palabras clave: memoria, dictatura brasileña, género, Bernardo Kucinski. 